\title{
Healthy and Sustainable Diets and Food Systems: the Key to Achieving Sustainable Development Goal 2?
}

\author{
Jessica Fanzo ${ }^{1}$ \\ Accepted: 21 October 2019 / Published online: 12 November 2019 \\ (C) The Author(s) 2019
}

\begin{abstract}
The Sustainable Development Goals (SDGs) are considered a unifying global goal setting agenda that every country is meant to achieve. One of those goals, SDG2, promises to ensure food security and nutrition within sustainable food systems. However, achieving that goal is riddled with uncertainty because of the way in which the world currently produces and consumes foods. The global trends of diets and the food systems that produce those diets suggest that they are neither healthy nor sustainable, which has implications for achieving SDG2. This paper characterizes the current state of global diets and food systems, the concept of "healthy and sustainable diets," and the ethical considerations to achieving healthy and sustainable diets for sustainable development.
\end{abstract}

Keywords Sustainable diets · Nutrition transition · Sustainable development goals · Trade-offs · Animal source foods

\section{Introduction}

Food systems consists of all the inputs (environment, people, processes, infrastructures, institutions, etc.), activities and actors that relate to the production, processing, distribution, preparation and consumption of food, and the outcomes of these activities, namely nutrition and health, economic, social and environmental outcomes (HLPE 2014). Food systems are meant to provide the diversity of food that make up diets (Glopan 2016).

The ideal diet is one that is healthy, of sufficient quality and quantity, affordable, safe and culturally acceptable for human ideal nutrition and health status (Drewnowski 2014; Donati et al. 2016). However, something has gone awry (Afshin et al. 2019; DI 2018; Glopan 2016; Swinburn et al. 2019; FAO et al. 2019). Every country is affected by malnutrition at least in

Jessica Fanzo

jfanzo1@jhu.edu

1 The Berman Institute of Bioethics, The Nitze School of Advanced International Studies and The Bloomberg School of Public Health, Johns Hopkins University, Deering Hall 207, 1809 Ashland Ave, Baltimore, MD 21205, USA 
some form, whether it be undernutrition, micronutrient deficiencies, or overweight and obesity with some countries struggling with multiple forms (DI 2018). These forms of malnutrition present a major impediment to achieving sustainable development, with crippling consequences for human health, the environment and human capabilities.

While there are multiple underlying determinants of malnutrition, sub-optimal diets serve as a common, factor for poor nutrition outcomes (Lartey 2008; Imamura et al. 2015; Mozaffarian and Forouhi 2018). Knowing that diets, be they healthy or unhealthy, come from food systems, it is important to understand how food systems are changing and their ability to deliver nutritious diets while at the same time minimizing negative environmental impacts (Ranganathan et al. 2016a, b; Willett et al. 2019).

With urbanization and globalization, economic growth, and food industry consolidation, food systems and actors have become more complex with potential negative impacts on health and nutrition (Glopan et al. 2016; HLPE 2017). There are also global calls for concern that food systems are less sustainable, producing significant environmental degradation and pollution (IPCC 2019; Willett et al. 2019; WRI 2019). If current trends continue, the effects of these increases will be felt most strongly in low and middle-income countries that are already grappling with double and triple forms of malnutrition (DI 2018; HLPE 2017).

The Sustainable Development Goals (SDGs) - the world's main accountability tool for sustainable development over the coming 15 years - have ambitious targets embedded within their goals that include food security, nutrition, climate stability, sustainable consumption and human justice and dignity. One of these targets, SDG2, focuses on eliminating hunger and malnutrition and improving the sustainability of food systems. Achieving this goal presents challenges when looking at the current trends and trajectories of diets and food systems, and solutions to these challenges engages a range of compelling ethical values that must be examined. This purpose of this paper is to examine global progress in achieving SDG2 and the role of diets and food systems in achieving SDG2, highlight the challenges of fulfilling sustainable diets, and suggest some ethical issues associated with sustainable diets to address SDG2.

\section{The Mandate of the Sustainable Development Goals}

\section{The Sustainable Development Goals}

The Sustainable Development Goals were agreed upon in September of 2015 during the United Nations (UN) General Assembly following the Millennium Development Goals (MDGs), which came to an end in 2015. The SDGs build upon the achievements of the MDG era and are meant to put every country on a path towards sustainable development. They are considered a blueprint, a road map, or a codex so-to-speak to achieve a better and more sustainable future for everyone (Byerlee and Fanzo 2019).

There are seventeen aspirational SDGs that span the necessary bricks and mortar for sustainable development - development that meets the needs of the present population without compromising the ability of future generations to meet their own needs for a resilient future for both people and the planet. To this end, there must be promotion of sustainable, inclusive and equitable economic growth, creating greater opportunities for all, reducing inequalities, raising basic standards of living, fostering equitable social development and inclusion, and promoting integrated and sustainable management of natural resources and ecosystems (UN 2015). 
While the MDGs focused mainly on developing countries looking to end poverty, the SDGs are universal to all countries - low-, middle-, and high-income countries to end all forms of malnutrition, improve health, tackle climate change and environmental degradation, fight inequalities and ensure social justice. They are to make certain that no one is left behind and that development works for everyone. They are meant to be broader in scope, cover more ground and go further than the MDGs in addressing inequalities, building sustainable jobs, cities and industry, protecting oceans and ecosystems, mitigating climate change, and putting into place peace and justice (DI 2017). While not legally binding, countries are expected to take ownership and establish national frameworks and guidance on how to achieve the seventeen goals through improved means of implementation, and mobilization of finance, capacity building technology and data and institutions (Byerlee and Fanzo 2019; Fanzo 2018).

\section{SDG2 Is Pivotal to Sustainable Development}

SDG2 is the goal within the larger agenda that focuses on ending hunger and malnutrition, increasing agriculture productivity, and improving food system sustainability. The targets within SDG2 are lofty (Box 1). Over half of the SDGs relate to global food security and nutrition, with SDG2 being the most critical, but also including the goals that relate to poverty, gender equality, health, water and sanitation, responsible production and consumption, and climate change (FAO et al. 2018; DI 2017).

\section{Box 1: The SDG2 Targets}

2.1 By 2030, end hunger and ensure access by all people, in particular the poor and people in vulnerable situations, including infants, to safe, nutritious and sufficient food all year round.

2.2 By 2030, end all forms of malnutrition, including achieving, by 2025 , the internationally agreed targets on stunting and wasting in children under 5 years of age, and address the nutritional needs of adolescent girls, pregnant and lactating women and older persons.

2.3 By 2030, double the agricultural productivity and incomes of small-scale food producers, in particular women, indigenous peoples, family farmers, pastoralists and fishers, including through secure and equal access to land, other productive resources and inputs, knowledge, financial services, markets and opportunities for value addition and non-farm employment.

2.4 By 2030, ensure sustainable food production systems and implement resilient agricultural practices that increase productivity and production, that help maintain ecosystems, that strengthen capacity for adaptation to climate change, extreme weather, drought, flooding and other disasters and that progressively improve land and soil quality.

2.5 By 2020, maintain the genetic diversity of seeds, cultivated plants and farmed and domesticated animals and their related wild species, including through soundly managed and diversified seed and plant banks at the national, regional and international levels, and promote access to and fair and equitable sharing of benefits arising from the utilization of genetic resources and associated traditional knowledge, as internationally agreed.

2.A Increase investment, including through enhanced international cooperation, in rural infrastructure, agricultural research and extension services, technology development and plant and livestock gene banks in order to enhance agricultural productive capacity in developing countries, in particular least developed countries.

2.B Correct and prevent trade restrictions and distortions in world agricultural markets, including through the parallel elimination of all forms of agricultural export subsidies and all export measures with equivalent effect, in accordance with the mandate of the Doha Development Round.

2.C Adopt measures to ensure the proper functioning of food commodity markets and their derivatives and facilitate timely access to market information, including on food reserves, in order to help limit extreme food price volatility. 


\section{Status of Progress on SDG2}

Progress made on SDG2 targets is varied. After a prolonged decline, world hunger appears to be on the rise again. Conflict, drought and disasters linked to climate change are among the key factors causing this reversal in progress (FAO et al. 2018). The proportion of undernourished people worldwide increased slightly from $10.6 \%$ in 2015 to $10.8 \%$ in 2018 . This translates to 821 million people worldwide in 2018, up from 785 million in 2015 (FAO 2019).

In 2018, 151 million children under age 5 suffered from stunting (low height for their age), 51 million suffered from wasting (low weight for height), and 38 million were overweight (Unicef et al. 2018). Stunting among children under five years of age is declining, albeit it slowly, with overall prevalence down from $32.6 \%$ in 2000 to $22.2 \%$ in 2017 . Regionally, Asia has declined from $38.1 \%$ to $23.2 \%$ since 2000 and Latin America has declined from $16.9 \%$ to 9.6\%. The prevalence of stunting has also declined in Africa from 38.32 to $30.3 \%$ since 2000 (Unicef et al. 2018).

Of the 150.8 million stunted, 58.7 million live in Southern Asia. Same with wasting - more than half of wasted children, 26.9 million, live in Southern Asia. Of the 38.3 million children overweight, Southern and East Asia have 5.4 million and 4.8 million children grappling with early overweight onset respectively (Unicef et al. 2018). While adult overweight and obesity is not tracked within the SDG framework, it is central to the nutrition agenda. Two billion adults are overweight in which 678 million are obese (NCD Risc 2018). Globally, women have had shown a higher prevalence of both overweight and obesity compared to men every year since 1990. Data on the prevalence of overweight adults increased from $35.7 \%$ in 2010 to $38.9 \%$ in 2016. Obesity prevalence in adults increased from $11.2 \%$ in 2010 to $13.1 \%$ in 2016 (DI 2018).

Likewise, anemia is not tracked within the SDG framework. However, one and three women of reproductive age suffer from anemia which can have life-long impacts on work and personal capacity and cognitive functioning. Women with anemia stands at $32.8 \%$ and has risen (DI 2018).

Figure 1 shows the progress made on these core set of nutrition indicators since 2012, with projections out to 2025, and 2030, the deadline to achieve the SDGs (FAO 2019). Strong policies with substantive investments will have to be stepped up to achieve the 2030 projections across all of the indicators.

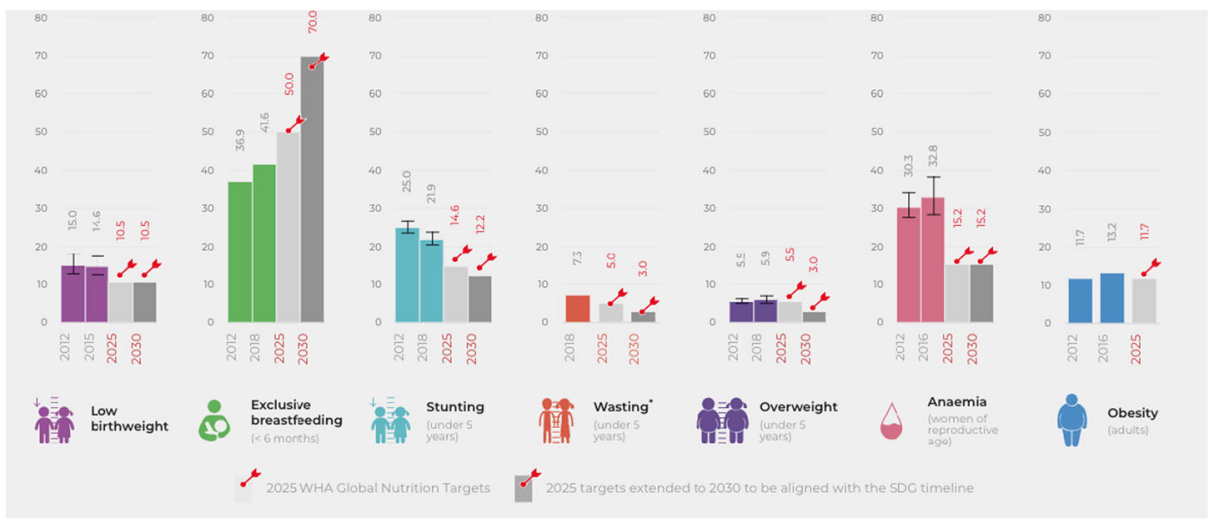

Fig. 1 The prevalence of different forms of malnutrition from 2012 to 2018 with estimates in achieving 2025 World Health Assembly Targets and 2030 SDG targets. Source: FAO 2019 


\section{The Essentiality of Food Systems and Diets for Sustainable Development}

\section{Food Systems Are Central for Achieving the SDGs}

A food system consists of all the inputs (environment, people, processes, infrastructures, institutions, etc.), activities and actors that relate to the production, processing, distribution, preparation and consumption of food, and the outcomes of these activities, namely nutrition and health, economic, social and environmental outcomes (HLPE 2014). With increasing urbanization, income growth and globalization, food systems have become more complex and nuanced with multiple actors shaping their transformation.

Food systems have distinct entry points for achieving the multiple objectives of the SDGs: "In our increasingly interconnected world, strengthened agriculture and food systems have a critical role to play in achieving the targets of the Sustainable Development Goals of eliminating poverty and hunger, and increasing our resilience to climatic and economic shocks" (Byerlee and Fanzo 2019; FAO 2016). Food systems embody complex relationships between the environmental, economic and social pillars of sustainable development, as part of a collaborative network that integrates food production, processing, distribution, consumption and waste management (IFPRI 2016). To achieve the SDGs, society expects for food systems to be that much more efficient, healthy, and inclusive, with supporting policies and legal frameworks that address income inequality, support livelihoods, and ensure resiliency. Yet, shaping complex food systems is never easy (Denning 2016; Garnett 2017). A plethora of formal and informal actors, vested interests, and technology and innovation inequities make shaping food systems all the more challenging (IPES 2017).

\section{Diets, a Central Output of Food Systems, in Turn, Shape Nutrition}

Diets comprise the foods that an individual consumes that meet energy needs, provide the diversity of safe foods to meet nutritional needs, that are accessible and affordable, and that enrich and preserve social and cultural traditions (USDA 2015). Dietary patterns are the quantities and combinations of those said foods and beverages in diets and the frequency of how they are habitually consumed (Hu et al. 1999; Kant 2004; Mozaffarian and Ludwig 2010).

While there have been attempts to define and characterize diets or dietary patterns that are "healthy" or "nutritious", there is less agreement on what is considered a healthy or nutritious food (HLPE 2017). The International Conference on Nutrition Rome Declaration states, "nutrition improvement requires healthy, balanced, diversified diets, including traditional diets where appropriate, meeting nutrient requirements of all age groups and all groups with special nutrition needs, while avoiding the excessive intake of saturated fat, sugars and sodium, and virtually eliminating trans fats, among others" (WHO and FAO 2014). While this definition encompasses a general picture of what constitutes a healthy diet, it does not provide detailed guidance on the specific constituents and quantities necessary to consume an optimal healthy diet. There has been a wealth of long-term epidemiology studies describing certain "territorial diets" such as the Mediterranean, Nordic or Japanese diets and their impacts on human health (Kuhnlein et al. 2006; Lipski 2010; Trichopoulou et al. 2014). These diets have shed light on compositions of diets, and their impacts on certain disease outcomes as well as protective effects (Eleftheriou et al. 2018; Martínez-González 2016).

While diets shape human health and nutrition outcomes, nutrition and health, in turn, affect human capital. Optimal nutrition is a basic building block of human capital and, as such, 
contributes to economic development (Shekar et al. 2006). Human capital is the skills, knowledge, and experience possessed by an individual that add value to a country or community. Nutrition early in life is essential to adult productivity and capital. Improving nutrition contributes to productivity, economic development, and poverty reduction by improving physical work capacity, cognitive development, school performance, and health by reducing disease and mortality (Shekar et al. 2006). Because nutrition plays such an essential role for human capability, or a person's freedom or opportunity to achieve their full potential that Martha Nussbaum articulated (Nussbaum 2011), it is an avenue to address the SDGs.

\section{Current State of Healthy, Sustainable Diets}

Sustainability implies a state whereby the needs of the present and local population can be met without diminishing the ability of future generations or populations in other locations to meet their needs or without causing harm to the environment and natural assets (Brundtland 2018). Globally, it is recognized that the health of human beings cannot be isolated from that of ecosystems (TEEB 2018).

\section{The Concept of Healthy, Sustainable Diets}

Recently, the concept of sustainable food systems and diets has grown in importance. It is thought that while the benefit of the global food system is a safe, nutritious, and consistent food supply, that same system also places significant strain on land, water, air, and other natural resources. The idea of "sustainable diets," which combines dietary recommendations with healthier environments and consumers, was proposed in the 1980s, using perhaps different terminology, but has recently been revived in the context of more emphasis on sustainable development. Newer concepts of "sustainable diets" are those that promote environmental and economic stability through low-impact and affordable foods, while at the same time improving public health through adequate nutrition (Johnston et al. 2014; Mason and Lang 2017).

FAO further defined sustainable diets as "those diets with low environmental impacts which contribute to food and nutrition security and to healthy life for present and future generations." Sustainable diets are protective and are respectful of biodiversity and ecosystems; they are culturally acceptable, accessible, economically fair and affordable, nutritionally adequate, safe and healthy while at the same time optimizing natural and human resources (Burlingame and Dernini 2012).

Defining sustainable diets is important, yet more work is needed on what constitutes a sustainable diet from environmental, biological, cultural and health standpoints, at the global, regional, local and individual levels (Jones et al. 2016). Better measurements and indicators are needed to assess the impact of the various determinants of sustainable diets and the potential synergies and trade-offs associated with any recommendations aimed at increasing the sustainability of our food system (Auestad and Fulgoni, 2015; Meybeck and Gitz 2017). It also remains unclear how these diets can be assessed within our global food system and how environmental sustainability in our consumption patterns and dietary goals can be achieved (Johnston et al. 2014; Jones et al. 2016). Auestad and Fulgoni (2015) argue that there is a need for better guidance on what constitutes healthy, sustainable diets, but this is difficult with the current gaps in research of what works to achieve these diets. Beyond just issues of evidence of 
what works, in certain contexts, there is also a lack of "consensus and political will to act in the face of perceived competing agendas between promoting healthy and sustainable diets and promoting economic growth" (Lawrence et al. 2015).

\section{The Health Status of Diets}

One of the major causes of malnutrition and its subsequent health outcomes is diets (Afshin et al. 2019; Willett et al. 2019; Swinburn et al. 2019). Unhealthy diets are now one of the top risk factors globally for deaths and disability-adjusted life-years (DALYs) lost (GBD 2017; Afshin et al. 2019), surpassing for example tobacco smoking and high blood pressure (Fig. 2). These unhealthy diets are those low in fruits, vegetables, whole grains, nuts and seeds, milk, fiber, calcium, seafood and fish high in omega-3 fatty acids, and polyunsaturated fatty acids, and diets high in red meat, processed meat (smoked, cured, salted or chemically preserved), sugar-sweetened beverages, trans fats and sodium (Forouzanfar et al., 2015; Imamura et al. 2015; Lawrence et al. 2019; Willett et al. 2019). Highly-processed foods are usually characteristically high in salt, trans fats and added sugar (Baker and Friel 2014; Monteiro et al., 2013). Diets serve as a major risk factor for non-communicable diseases including diabetes and heart disease (Branca et al. 2019; Mozafarrian et al. 2018; Yakoob et al. 2016). Still, child and maternal undernutrition is a significant risk factor of morbidity and mortality, particularly in low-income countries (Black et al. 2013; Swinburn et al. 2019).

Global dietary patterns have been changing, affecting people in all parts of the world (Popkin et al. 2012; Glopan 2016; HLPE 2017). While some of these changes have had positive impacts on health, some have been negative. The "nutrition transition," illustrated in Fig. 3, refers to these changes in dietary patterns as populations undergo demographic transition, urbanization and economic development. These shifts subsequently influence epidemiological disease patterns among those populations that are undergoing lifestyle changes (Popkin et al. 2012). Figure 3 places food systems or these transitions as established by the UN High Level Panel of Experts Report on Food Systems in Nutrition (2017), into three broad types which are illustrated below.

In traditional, rural food systems, people have access to more locally produced foods, and less highly-processed food. A majority of the diet is comprised of staple grains and tubers, legumes and some seasonal vegetables and fruits, with less access to animal source foods. Food supply chains are often short, informal, and have limited diversity in some
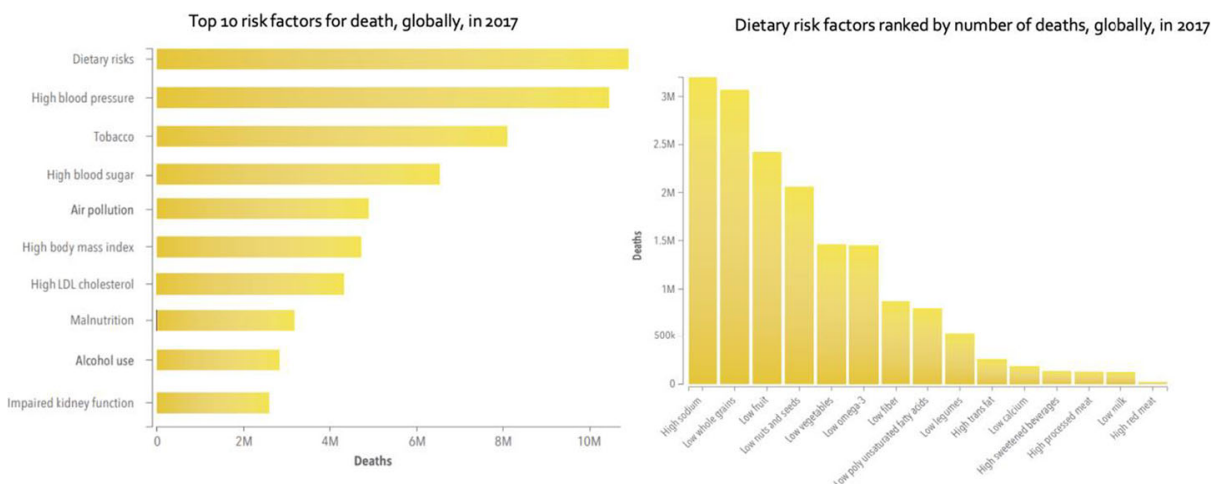

Fig. 2 Sub-optimal diets are now a major risk factor of mortality. Source: Afshin et al. 2019 


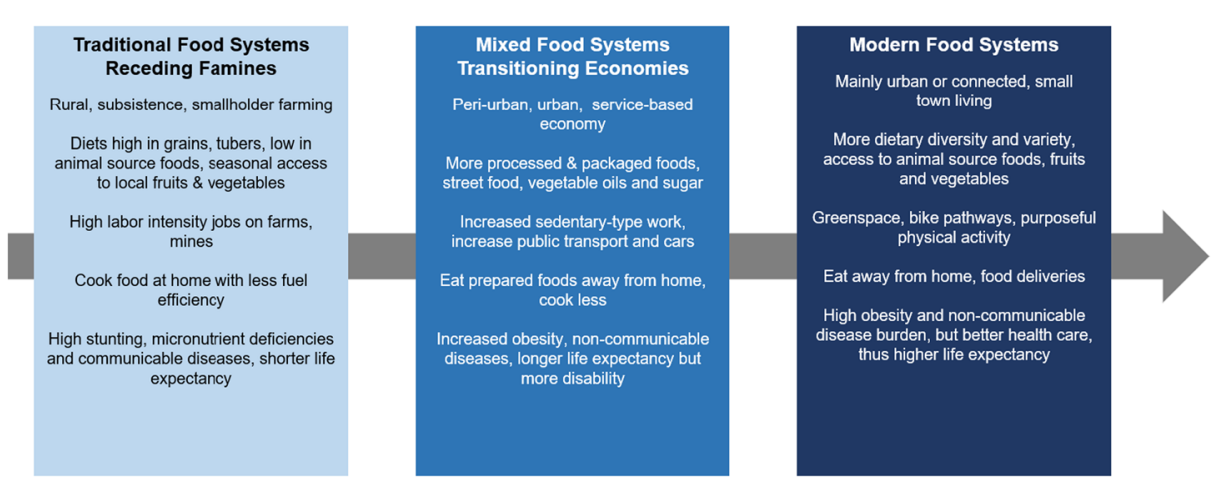

Fig. 3 The nutrition transition. Source: UN HLPE Report 2017

places. Populations living in these systems tend to be more vulnerable to infectious diseases, wasting and/or stunting, high maternal and child mortality, and other factors resulting in a shorter life expectancy. Even if famines have receded, people still experience seasonal hunger (HLPE 2017).

In transitioning economies, urbanization and income growth influence lifestyle changes and changing, mixed food systems. Urbanization can also cause demographic and technological changes such as more women entering the labor force, which opens new career and lifestyle opportunities (Seto and Ramankutty, 2016). These changes in income and routine also affect food preferences with an increased demand for convenient foods such as street food, fast food, and highly-processed foods that are affordable, convenient, and easier to cook (Drewnowski and Popkin, 1997). Populations may be dealing with multiple burdens of malnutrition, but overall, overweight, obesity and non-communicable disease replaces high burdens of undernutrition (Dietz 2017; Popkin 2015; Popkin 2017). This outcome results in longer life spans but higher disability with suboptimal quality of life. The architecture of many cities, also known as the built environment, is often not sufficient to promote physical activity in many economically transitioning countries, which has important implications for obesity and noncommunicable diseases (Kearney 2010).

In more progressive, "modern" food systems, there is a plethora of food outlets - some healthy, some not as healthy - with a heavy reliance on hyper- and supermarkets. These modern systems afford people with the skills and tools to change behavior which can reverse the negative tendencies of the preceding patterns, although currently this is rare, even in highincome countries. It is that that in these progressive places, people are more concerned with their health, consciously eat healthier foods, and increase their levels of physical activity, which facilitates healthy aging (Popkin 2017). These changes may be due to increased education and awareness or may occur out of necessity in the case of people who suffer from diet-related non-communicable diseases themselves (Popkin et al. 2012). As a result, life span is long, and disability decreases.

These patterns of the "nutrition transition" do not necessarily indicate that every food system, and every country will follow this pattern and not every country has a set fate. There are ways to bypass the unhealthy aspects of these patterns and, for low- and middle-income countries; it is possible for transitioning countries to avoid the path that some high-income countries have taken. Still, it will take a concerted effort to avoid these trends and their detrimental impacts (HLPE 2017). 


\section{The Environmental Sustainability Status of Diets}

The literature has described in some detail the pattern of diets prevalent in many middle- and high-income countries, as well as those transitioning economies, from both a health and environmentally sustainable perspective (Garnett 2016). They are often characterized as high energy intake, sub-optimal dietary diversity, and high intake of vegetable oil and sugar and animal source foods (ASF) (Roos et al. 2017). Production of ASF, and particularly that of beef which is a common source of protein in Western diets, contributes significantly to negative environmental outcomes (Tilman and Clark 2014; Poore and Nemecek 2018). Additionally, such diets have negative impacts on cardiovascular disease, stroke, and diabetes (Mozaffarian 2016; Springmann et al. 2017).

There are diets that can be either environmentally sustainable and not healthy, or healthy and not environmentally sustainable (Garnett 2017). For example, diets with low dietary diversity and which derive the majority of dietary energy from starches and grains, have lower environmental footprints. These low-impact diets often fail to address individuals' micro- and macronutrient needs (Garnett 2014). They can also be associated with high levels of sugar and salt consumption (Alesandrowicz et al. 2016) and low levels of key micronutrients, such as iron and zinc (Payne et al. 2016). Such diets are common among many individuals in lowincome countries and contribute significantly to the global burden of undernutrition and micronutrient deficiencies (Afshin et al. 2016).

Similarly, there are healthy diets that negatively impact the environment. Diets with high amounts of dairy, lean meat, fish and seafood, nuts, and fruits and vegetables, and minimal amounts of processed foods and sugars, might be healthy, but can come at a high environmental cost (Garnett 2016). For instance, certain fish and seafood production practices negatively affect greenhouse gas emissions, land and water quality, and biodiversity, nut production can have a high blue (irrigation) water footprint, and lean meats have differential impacts on greenhouse gas emissions, crop diversity, water use, and pollution. (Tilman and Clark 2014; Farmery et al. 2017; Downs and Fanzo, 2015; Fry et al. 2016; Alesandrowicz et al. 2016; Tom et al. 2016; Garnett et al. 2017).

Which type of diet is good for both human and environmental health? Some research suggests that it is a diet that includes more fruits and vegetables, and less ASF, sugars, and vegetable oils (Roos et al. 2017; Garnett 2016; Mozafarrian 2016). Dietary patterns that replace animal-based foods with plant-based alternatives confer significant environmental benefits (Payne et al. 2016) Additionally, diets that replace ruminants with other alternatives, such as fish, poultry and pork, show reduced environmental impacts, as well as with plant-based alternatives (Auestad and Fulgoni 2015; Hallstrom et al. 2015; Springmann et al. 2018a).

Recent literature reviews summarized the environmental impacts of dietary patterns (Joyce et al. 2014, Auestad and Fulgoni 2015, Hallström et al. 2015, Nelson et al. 2016), including three that explicitly explored health outcomes alongside environmental outcomes (Aleksandrowicz et al. 2016, Payne et al. 2016, Perignon et al. 2016). These reviews found that dietary patterns that replace animal-based foods with plant-based alternatives confer the greatest environmental benefits (Springmann et al. 2018a; Springmann et al. 2018b). Vegan and vegetarian diets were associated with significant reductions in greenhouse gas emissions, water and land use. (Aleksandrowicz et al. 2016). Diets that consumed more fish, poultry and pork, and less ruminants, also show reduced environmental impacts, but less so than plantbased alternatives (Auestad and Fulgoni 2015, Hallström et al. 2015). 
However, the environmental benefits of sustainable dietary patterns do not consistently correlate with the health benefits. In general, many studies report reductions in allcause mortality and in the risks of cardiovascular disease, colorectal cancer and diabetes mellitus for more sustainable dietary patterns (Aleksandrowicz et al. 2016; Nelson et al. 2016). However, these findings have been largely heterogeneous and are often not statistically significant (Payne et al. 2016). Additionally, sustainable diets with lower greenhouse gas emissions are associated with higher levels of sugar and salt consumption (Aleksandrowicz et al. 2016), and decreased levels of key micronutrients, such as zinc (Payne et al. 2016).

As such, recommendations of healthy sustainable diets can be particularly problematic, especially in low- and middle-income countries that already struggle with nutrition transitions and micronutrient deficiencies. In countries where undernutrition of women and children contributes more to the burden of disease than metabolic dietary risk factors (e.g. SubSaharan Africa and South-East Asia), it is essential that we not exacerbate high rates of undernutrition and micronutrient deficiencies through diet (GBD 2017; Springmann et al. 2017). For example, vegan diets might not be appropriate for populations with high prevalence of undernutrition and micronutrient deficiencies. Increasing animal-sourced food consumption might improve health outcomes for these groups, due to content and bioavailability of key micronutrients (Perignon et al. 2017).

In summary, diets can produce co-benefits for human and environmental health. Harnessing these co-benefits requires an integrated approach to health and sustainability that considers the complex linkages and feedback loops between food systems, diets, human health and the environment.

\section{Ethical Considerations of Healthy and Sustainable Diets}

There are ethical considerations to be elucidated on how realistic healthy, sustainable diets are with the current population pressures, economic instability, and increasingly inequitable food supplies and demands.

There are profound inequities both globally and within countries, with respect to access to and affordability of nutritious foods (Headey and Alderman 2019). The increased demand for certain resource-intensive foods has serious potential ramifications for both climate change and human health (Mearns and Norton, 2010; Willett et al. 2019; IPCC 2019). There are four ethical points of contention.

First, overconsumption and escalating demand for livestock have created ethical conflicts over ensuring animal welfare and limiting demands on the environment (Garnett, 2009; Stokstad, 2010; Willett et al. 2019). In addition, many of these livestock production system use grain as the main feed for their animals, resulting in a significant amount of land devoted to growing feed (Lappe et al. 2013). One-third of global cereal crop production is fed to animals (Godfray et al. 2010), while we know that the world still faces seasonal hunger periods and in the last few years, famines in several countries (FAO 2019). This presents an ethical dilemma on feeding people to stave off hunger and food insecurity or feeding animals to keep up a changing dietary demand of consumers with disposable income to spend on costly foods. There are also concerns of the role of highly-processed foods that are considered "empty calories" and contain high amounts of unhealthy fats, sugars and salt, on health and sustainability (Lawrence et al. 2019). 
Second, the distribution and access to costly foods, such as ASF, is currently not equitable if we consider these foods as being critically important for human health in that they provide iron, zinc and other vital micronutrients (Varijakshapanicker et al. 2019). There needs to be a re-setting of the balance to ensure that access or better distributed (Michalk et al. 2019. While there are low-resource alternative sources that should be considered in filling nutrient gaps for all countries to consider, they are often not in high demand with the exception of fish (Hicks et al. 2019). Farmed fish, mollusks, insects and protein-rich plant foods can serve as important and alternative sources of nutrient rich foods (including protein, fatty acids, zinc, iron, B12, Vitamin D), as compared to muscle and organ meats from livestock (Hicks et al. 2019).

Third, the issue of eating ASF is also a matter of consumer preferences, taste, and social standing. And putting restrictions or limitations on meat could infringe on issues of self liberties. Popkin noted: "We have created societies in the West that value and consume meat, dairy, poultry, fish and seafood. Over generations, a particular way of life has been promoted and this has shifted expectations about diet to include large amounts of animal sourced foods. The developing world wants to eat the same way and is rapidly increasing its demand for meat and other animal products" (Popkin 2011). Even if eating "higher status" ASF is not essential for optimal nutrition, does it matter ethically that people have inequitable access to foods that give them pleasure and social status? The EAT Lancet Commission (Willett et al. 2019) argued for a flexitarian diet that was lower in ASF, however there was significant criticism on whether this diet is locally adaptable, and culturally, socially and geographically appropriate. Many critics struggled to find how these recommendations fit within the local context for specific populations (Lawrence et al. 2019).

\section{Living with Tradeoffs in the Era of Sustainable Development}

There is no ethically simple way to reconcile these competing demands in the face of growing economies, international trade, globalization, and urbanization (FAO, 2013). Is it possible for everyone to consume a sustainable diet for both human and planetary health that fits well within the mandate of SDG2? And if yes, what would global cooperation look like to get to that goal??

Food systems require and influence three major societal outcomes - economic vitality, environmental sustainability, and social inclusion and human health. Economic vitality is made through different policies, such as trade and employment, are influenced by food systems and vice versa. The environmental sustainability occurs through the protection of ecosystem services and natural capital that in turn have co-benefits with food systems. Social inclusion and human health are very much dependent on food security, nutrition, food culture and animal welfare. Although one change in the system may bring multiple outcomes, these outcomes may not all be what is considered progress. A nutritional intervention may have an unintended consequence for environmental, economic, and social outcomes or an economic incentive may have profound impacts on the environment or natural resource base. Therefore, even though the food system is complex, it is important to consider the synergies, trade-offs, and negative externalities that result from changes across the entire food system (Ingram 2011).

There will be inherent trade-offs depending on what set of outcomes are chosen. Economic gains may have negative impacts on diets or the environment. In achieving SDG2, there will be negative impacts on other SDGs and vice versa. We all want food systems that are 
sustainable, end hunger, improve nutrition and improve economies. "But not everyone has the same vision on "how to get there and what that may look like. The ethical perspectives people bring to the food sustainability problem influence both their use of the evidence and the solutions they propose and these often lead to stakeholders arguing at cross-purposes, the result being conflict, or inaction" (Garnett 2017). The solutions proposed are often different and can conflict with other goals. It is important to be realistic on what outcomes can be delivered upon and what trade-offs the world is willing to live with.

\section{Final Thoughts on Healthy and Sustainable Diets}

The decision of what to eat is inextricably linked to the ethics of how that choice affects environmental sustainability and human well-being. If certain resource-intense foods are considered critically important for human health, then their distribution and access must be made equitable - an existing imbalance that needs to be addressed. The dietary choices of people in high-income countries have significant ramifications for less wealthy populations. Energy intensive lifestyles and diets of those in HICs are significant anthropogenic contributors to climate change. However, economically poor households are likely to experience a disproportionate burden of the impacts of climate change (Olsson et al., 2014). The food security of those households will most likely not improve under climate variability, and diets will actually deteriorate along with nutrition outcomes. Those who are wealthier will suffer less even though their choices have far-reaching consequences.

Where there is sufficient scientific and ethical justification to strive for healthy, sustainable diets, how can policies and interventions be constructed and implemented in specific national contexts? Is it ethically acceptable to mandate specific interventions such as taxes, incentives, nudges, and subsidies without regressive consequences? It will be important to identify morally relevant differences between middle-income countries (where the aim would be to prevent meat consumption levels from reaching a threshold), and high-income countries (where the aim would be to alter already entrenched patterns of consumption) as compared to low-income countries where options and choices are fewer and far between. It will also be important to identify morally relevant obligations and interventions to promote access to healthy, sustainable diets that allow for sustainable development for all.

Open Access This article is distributed under the terms of the Creative Commons Attribution 4.0 International License (http://creativecommons.org/licenses/by/4.0/), which permits unrestricted use, distribution, and reproduction in any medium, provided you give appropriate credit to the original author(s) and the source, provide a link to the Creative Commons license, and indicate if changes were made.

\section{References}

Afshin, A., Sur, P.J., Fay, K.A., Cornaby, L., Ferrara, G., Salama, J.S., Mullany, E.C., Abate, K.H., Abbafati, C., Abebe, Z. and Afarideh, M., 2019. Health effects of dietary risks in 195 countries, 1990-2017: a systematic analysis for the Global Burden of Disease Study 2017. The Lancet, 393(10184): 1958-1972.

Aleksandrowicz, L., R. Green, E.J.M. Joy, P. Smith, and A. Haines. 2016. The impacts of dietary change on greenhouse gas emissions, land use, water use, and health: A systematic review. PLoS One 11 (11): e0165797.

Auestad, N., and V.L. Fulgoni III. 2015. What current literature tell us about sustainable diets: Emerging research linking dietary patterns, environmental sustainability, and economics. Advances in Nutrition 6 (1): 19-36. 
Baker, P., and S. Friel. 2014. Processed foods and the nutrition transition: Evidence from Asia. Obesity Reviews 15 (7): 564-577.

Black, R.E., C.G. Victora, S.P. Walker, Z.A. Bhutta, P. Christian, M. De Onis, M. Ezzati, S. Grantham-McGregor, J. Katz, R. Martorell, and R. Uauy. 2013. Maternal and child undernutrition and overweight in low-income and middle-income countries. The Lancet 382 (9890): 427-451.

Branca, F., A. Lartey, S. Oenema, V. Aguayo, G.A. Stordalen, R. Richardson, M. Arvelo, and A. Afshin. 2019. Transforming the food system to fight non-communicable diseases. Bmj 364: 1296.

Brundtland, G.H. 2018. Report of the world commission on environment and development: our common future. Oslo, 20 Mar 1987.

Burlingame, B., and S. Dernini. 2012. Sustainable Diets and Biodiversity: Directions and Solutions for Policy, Research and Action. International Scientific Symposium, Biodiversity and Sustainable Diets United Against Hunger, FAO Headquarters, Rome, Italy, 3-5 November 2010. In Sustainable Diets and Biodiversity: Directions and Solutions for Policy, Research and Action. International Scientific Symposium, Biodiversity and Sustainable Diets United Against Hunger, FAO Headquarters, Rome, Italy, 3-5 November 2010. Food and Agriculture Organization of the United Nations (FAO).

Byerlee, D., and J. Fanzo. 2019. The SDG of zero hunger 75 years on: Turning full circle on agriculture and nutrition. Global Food Security 21: 52-59.

Denning. 2016. The road to good nutrition. Netherlands: DSM.

DI. 2017. Global nutrition report. Bristol: Development Initiatives.

DI. 2018. Global nutrition report. Bristol: Development Initiatives.

Dietz, W.H. 2017. Double-duty solutions for the double burden of malnutrition. The Lancet 390 (10113): 26072608.

Donati, M., D. Menozzi, C. Zighetti, A. Rosi, A. Zinetti, and F. Scazzina. 2016. Towards a sustainable diet combining economic, environmental and nutritional objectives. Appetite 106: 48-57.

Drewnowski, A. 2014. Healthy diets for a healthy planet. The American Journal of Clinical Nutrition 99 (6): 1284-1285

Drewnowski, A., and B.M. Popkin. 1997. The nutrition transition: New trends in the global diet. Nutrition Reviews 55 (2): 31-43.

Eleftheriou, D., V. Benetou, A. Trichopoulou, C. La Vecchia, and C. Bamia. 2018. Mediterranean diet and its components in relation to all-cause mortality: Meta-analysis. British Journal of Nutrition 120 (10): 10811097.

Fanzo, J. 2015. Ethical issues for human nutrition in the context of global food security and sustainable development. Global Food Security 7: 15-23.

Fanzo, J. 2018. Does global goal setting matter for nutrition and health? AMA Journal of Ethics 20 (10): 979986.

FAO. 2013. The State of Food and Agriculture. Rome, Italy.

FAO. 2019. The state of food security and nutrition in the world 2019. Rome, Italy.

FAO, IFAD, UNICEF, WFP and WHO. 2019. The State of Food Security and Nutrition in the World 2019. Safeguarding against economic slowdowns and downturns. Rome, FAO.

FAO, IFAD, UNICEF, WFP, and WHO. 2018. State of food security and nutrition. Rome, Italy.

FAO/WHO. 2014. Conference Outcome Document: Rome Declaration on Nutrition. Second International Conference on Nutrition, 19-21 November 2014: Rome, Italy.

FAO-WHO ICN2 Secretariat 2014. Second International Conference on Nutrition. Information Note on the Framework for Action. FAO. 2016. State of food insecurity. Rome, Italy.

Farmery AK, Gardner C, Jennings S, Green BS, Watson RA. 2017. Assessing the inclusion of seafood in the sustainable diet literature. Fish and Fisheries 18(3), 607-618.

Forouzanfar, M.H., L. Alexander, H.R. Anderson, V.F. Bachman, S. Biryukov, M. Brauer, R. Burnett, D. Casey, M.M. Coates, A. Cohen, and K. Delwiche. 2015. Global, regional, and national comparative risk assessment of 79 behavioural, environmental and occupational, and metabolic risks or clusters of risks in 188 countries, 1990-2013: A systematic analysis for the global burden of disease study 2013. The Lancet 386 (10010): 2287-2323.

Fry, J.P., D.C. Love, G.K. MacDonald, et al. 2016. Environmental health impacts of feeding crops to farmed fish. Environment International 91: 201-214.

Garnett, T. 2009. Livestock-related greenhouse gas emissions: Impacts and options for policy makers. Environmental Science \& Policy 12 (4): 491-503.

Garnett T. 2014. What is a sustainable healthy diet? A discussion paper. Food Climate Research Network (FCRN).

Garnett, T. 2016. Plating up solutions. Science (New York, N.Y.) 353 (6305): 1202.

Garnett, T., 2017. Livestock and climate change. In The Meat Crisis (pp. 31-51). Routledge. 
Garnett, T., M.C. Appleby, A. Balmford, I.J. Bateman, T.G. Benton, P. Bloomer, B. Burlingame, M. Dawkins, L. Dolan, D. Fraser, and M. Herrero. 2013. Sustainable intensification in agriculture: Premises and policies. Science 341 (6141): 33-34.

Garnett T, Godde C, Muller A, et al. 2017. Grazed and confused? Ruminating on cattle, grazing systems, methane, nitrous oxide, the soil carbon sequestration question - and what it all means for greenhouse gas emissions: Environmental change institute, University of Oxford.

GBD 2016 Risk Factors Collaborators. 2017. Global, regional, and national comparative risk assessment of 84 behavioural, environmental and occupational, and metabolic risks or clusters of risks, 1990-2016: A systematic analysis for the global burden of disease study 2016. Lancet 390 (10100): 1345-1422.

GloPan (Global Panel on Agriculture and Food Systems for Nutrition). 2016. Food systems and diets: Facing the challenges of the 21 st century. Foresight Report. London, UK. https://www.glopan. org/sites/default/files/Downloads/Foresight\%20Report.pdf. Accessed 1 Nov 2019.

Godfray, H.C.J., J.R. Beddington, I.R. Crute, L. Haddad, D. Lawrence, J.F. Muir, J. Pretty, S. Robinson, S.M. Thomas, and C. Toulmin. 2010. Food security: The challenge of feeding 9 billion people. Science 327(5967), 812-818.

Hallström, E., A. Carlsson-Kanyama, and P. Börgjesson. 2015. Environmental impact of dietary change: A systematic review. Journal of Cleaner Production 91: 1-11.

Headey, D.D., and H.H. Alderman. 2019. The relative caloric prices of healthy and unhealthy foods differ systematically across income levels and continents. The Journal of Nutrition. 149(11), 2020-2033

Hicks, C.C., P.J. Cohen, N.A. Graham, K.L. Nash, E.H. Allison, C. D’Lima, D.J. Mills, M. Roscher, S.H. Thilsted, A.L. Thorne-Lyman, and M.A. MacNeil. 2019. Harnessing global fisheries to tackle micronutrient deficiencies. Nature: $1-4$.

HLPE. 2014. Food losses and waste in the context of sustainable food systems. A report by the High Level Panel of Experts on Food Security and Nutrition of the Committee on World Food Security. Rome. http://www.fao. org/3/a-i3901e.pdf. Accessed 1 Nov 2019.

HLPE. 2017. Nutrition and food systems. A report by the High Level Panel of Experts on Food Security and Nutrition of the Committee on World Food Security, Rome.

Hu, F.B., E. Rimm, S.A. Smith-Warner, D. Feskanich, M.J. Stampfer, A. Ascherio, L. Sampson, and W.C. Willett. 1999. Reproducibility and validity of dietary patterns assessed with a food-frequency questionnaire. The American Journal of Clinical Nutrition 69 (2): 243-249.

IFPRI. 2016. Global nutrition report 2016: From promise to impact: Ending malnutrition by 2030. Washington, DC. http://www.ifpri.org/publication/global-nutrition-report-2016-promise-impact-ending-malnutrition2030. Accessed 1 Nov 2019.

Imamura, F., R. Micha, S. Khatibzadeh, S. Fahimi, P. Shi, J. Powles, D. Mozaffarian, and Global Burden of Diseases Nutrition and Chronic Diseases Expert Group (NutriCoDE. 2015. Dietary quality among men and women in 187 countries in 1990 and 2010: A systematic assessment. The Lancet Global Health 3 (3): e132e142.

Ingram, J. 2011. A food systems approach to researching food security and its interactions with global environmental change. Food Security 3 (4): 417-431.

Intergovernmental panel on climate change (IPCC). 2019. Special report on climate change, desertification, land degradation, sustainable land management, food security, and greenhouse gas fluxes in terrestrial ecosystems (SR2). London.

IPES-Food. 2017. What makes urban food policy happen? Insights from five case studies. http://www.ipes-food. org/images/Reports/Cities_full.pdf. Accessed 1 Nov 2019.

Johnston, J.L., Fanzo, J.C. and Cogill, B., 2014. Understanding sustainable diets: a descriptive analysis of the determinants and processes that influence diets and their impact on health, food security, and environmental sustainability. Advances in Nutrition 5(4), 418-429.

Jones, A.D., L. Hoey, J. Blesh, L. Miller, A. Green, and Shapiro L. Fink. 2016. A systematic review of the measurement of sustainable diets. Advances in Nutrition 7 (4): 641-664.

Joyce, A., J. Hallett, T. Hannelly, and G. Carey. 2014. The impact of nutritional choices on global warming and policy implications: Examining the link between dietary choices and greenhouse gas emissions. Energy and Emission Control Technologies 2: 33-43.

Kant, A.K. 2004. Dietary patterns and health outcomes. Journal of the American Dietetic Association 104 (4): 615-635.

Kearney, J. 2010. Food consumption trends and drivers. Philosophical Transactions of the Royal Society, B: Biological Sciences 365 (1554): 2793-2807.

Kuhnlein, H., B. Erasmus, H. Creed-Kanashiro, L. Englberger, C. Okeke, N. Turner, L. Allen, and L. Bhattacharjee. 2006. Indigenous peoples' food systems for health: Finding interventions that work. Public Health Nutrition 9 (8): 1013-1019. 
Lappé, F.M., J. Clapp, M. Anderson, R. Broad, E. Messer, T. Pogge, and T. Wise. 2013. How we count hunger matters. Ethics \& International Affairs 27 (3): 251-259.

Lartey, A. 2008. Maternal and child nutrition in sub-Saharan Africa: Challenges and interventions. Proceedings of the Nutrition Society 67 (1): 105-108.

Lawrence, M., B. Burlingame, M. Caraher, M. Holdsworth, R. Neff, and L. Timotijevic. 2015. Public health nutrition and sustainability. Public Health Nutrition 18 (13): 2287-2292.

Lawrence, M.A., P.I. Baker, C.E. Pulker, and C.M. Pollard. 2019. Sustainable, resilient food systems for healthy diets: The transformation agenda. Public health nutrition: 1-5.

Lipski, E. 2010. Traditional non-Western diets. Nutrition in Clinical Practice 25 (6): 585-593.

Martínez-González, M.A. 2016. Benefits of the Mediterranean diet beyond the Mediterranean Sea and beyond food patterns. BMC Medicine 14 (1): 157.

Mason, P., and T. Lang. 2017. Sustainable diets: How ecological nutrition can transform consumption and the food system. Routledge 4 (2) : 64-66.

Mearns, R. and Norton, A. 2010. Equity and vulnerability in a warming world: introduction and overview. Social dimensions of climate change: Equity and vulnerability in a warming world. Washington, DC: World Bank.

Meybeck, A., and V. Gitz. 2017. Sustainable diets within sustainable food systems. Proceedings of the Nutrition Society 76 (1): 1-11.

Michalk, D.L., D.R. Kemp, W.B. Badgery, J. Wu, Y. Zhang, and P.J. Thomassin. 2019. Sustainability and future food security - A global perspective for livestock production. Land Degradation \& Development 30 (5): 561-573.

Monteiro, C.A., J.C. Moubarac, G. Cannon, S.W. Ng, and B. Popkin. 2013. Ultra-processed products are becoming dominant in the global food system. Obesity Reviews 14 (S2): 21-28.

Mozaffarian, D. 2016. Dietary and policy priorities for cardiovascular disease, diabetes, and obesity - A comprehensive review. Circulation 133 (2): 187-225.

Mozaffarian, D., and N.G. Forouhi. 2018. Dietary guidelines and health—-Is nutrition science up to the task? Bmj 360: k822.

Mozaffarian, D., and D.S. Ludwig. 2010. Dietary guidelines in the 21st century-A time for food. Jama 304 (6): 681-682.

Mozaffarian, D., I. Rosenberg, and R. Uauy. 2018. History of modern nutrition science-Implications for current research, dietary guidelines, and food policy. Bmj 361: k2392.

NCD Risc 2019 http://ncdrisc.org/. Accessed 8 Nov 2019.

Nelson, M.E., M.W. Hamm, F.B. Hu, S. Abrams, and T.S. Griffin. 2016. Alignment of healthy dietary patterns and environmental sustainability: A systematic review. Advances in Nutrition 7 (6): 1005-1025.

Nussbaum, M. 2011. Creating capabilities. Cambridge: Harvard University Press.

Olsson, L., Opondo, M., Tschakert, P., Agrawal, A. and Eriksen, S.E., 2014. Livelihoods and poverty.

Payne, C.L.R., P. Scarborough, and L. Cobiac. 2016. Do low-carbon-emission diets lead to higher nutritional quality and positive health outcomes? A systematic review of the literature. Public Health Nutrition 19 (14): 2654-2661.

Perignon, M., F. Vieux, L.G. Soler, G. Masset, and N. Darmon. 2016. Improving diet sustainability through evolution of food choices: Review of epidemiological studies on the environmental impact of diets. Nutrition Reviews 75 (1): 2-17.

Perignon, M., F. Vieux, L.G. Soler, G. Masset, and N. Darmon. 2017. Improving diet sustainability through evolution of food choices: Review of epidemiological studies on the environmental impact of diets. Nutrition Reviews 75 (1): 2-17.

Poore, J., and T. Nemecek. 2018. Reducing food's environmental impacts through producers and consumers. Science 360 (6392): 987-992.

Popkin, B.M. 2011. Agricultural policies, food and public health. EMBO Reports 12 (1): 11-18.

Popkin, B.M. 2015. Nutrition transition and the global diabetes epidemic. Current Diabetes Reports 15 (9): 64.

Popkin, B.M. 2017. Relationship between shifts in food system dynamics and acceleration of the global nutrition transition. Nutrition Reviews 75 (2): 73-82.

Popkin, B.M., B.M. Popkin, L.S. Adair, and S.W. Ng. 2012. Global nutrition transition and the pandemic of obesity in developing countries. Nutrition Reviews 70 (1): 3-21.

Ranganathan, J., D. Vennard, R. Waite, P. Dumas, B. Lipinski, T. Searchinger, and GLOBALAGRI-WRR Model Authors. 2016a. Shifting diets for a sustainable food future. In Working paper, installment 11 of creating a sustainable food future. Washington, DC: World Resources Institute. Accessible at: http://www. worldresourcesreport.org. Accessed 1 Nov 2019.

Ranganathan, J., D. Vennard, R. Waite, P. Dumas, B. Lipinski, T.I.M. Searchinger, and M.A. GLOBAGRI-WRR. 2016b. Shifting diets for a sustainable food future. World Resources Institute. 
Röös, E., B. Bajželj, P. Smith, M. Patel, D. Little, and T. Garnett. 2017. Greedy or needy? Land use and climate impacts of food in 2050 under different livestock futures. Global Environmental Change 47 (supplement C): $1-12$.

Seto, K.C., and N. Ramankutty. 2016. Hidden linkages between urbanization and food systems. Science 352 (6288): 943-945. https://doi.org/10.1126/science.aaf7439.

Shekar, M., R. Heaver, and Y.K. Lee. 2006. Repositioning nutrition as central to development: A strategy for large scale action. World Bank Publications.

Springmann, M., D. Mason-D’Croz, S. Robinson, et al. 2017. Mitigation potential and global health impacts from emissions pricing of food commodities. Nature Climate Change 7 (1): 69-74.

Springmann, M., M. Clark, D. Mason-D’Croz, K. Wiebe, B.L. Bodirsky, L. Lassaletta, W. de Vries, S.J. Vermeulen, M. Herrero, K.M. Carlson, and M. Jonell. 2018a. Options for keeping the food system within environmental limits. Nature: 1.

Springmann, M., K. Wiebe, D. Mason-D'Croz, T.B. Sulser, M. Rayner, and P. Scarborough. 2018b. Health and nutritional aspects of sustainable diet strategies and their association with environmental impacts: A global modelling analysis with country-level detail. The Lancet Planetary Health 2 (10): e451-e461.

Stokstad, E. 2010. Despite progress, biodiversity declines. Science 329 (5997): 1272-1273.

Swinburn, B.A., V.I. Kraak, S. Allender, V.J. Atkins, P.I. Baker, J.R. Bogard, H. Brinsden, A. Calvillo, O. De Schutter, R. Devarajan, and M. Ezzati. 2019. The global syndemic of obesity, undernutrition, and climate change: The lancet commission report. The Lancet 393 (10173): 791-846.

TEEB. 2018. TEEB for Agriculture \& Food: Scientific and economic foundations. Geneva: UN Environment.

Tilman, D., and M. Clark. 2014. Global diets link environmental sustainability and human health. Nature 515 (7528): 518-522.

Tom, M.S., P.S. Fischbeck, and C.T. Hendrickson. 2016. Energy use, blue water footprint, and greenhouse gas emissions for current food consumption patterns and dietary recommendations in the US. Environment Systems and Decisions 36 (1): 92-103.

Trichopoulou, A., M.A. Martínez-González, T.Y. Tong, N.G. Forouhi, S. Khandelwal, D. Prabhakaran, D. Mozaffarian, and M. de Lorgeril. 2014. Definitions and potential health benefits of the Mediterranean diet: Views from experts around the world. BMC Medicine 12 (1): 112.

U.S. Department of Health and Human Services and U.S. Department of Agriculture. 2015-2020 Dietary Guidelines for Americans. 8th Edition. December 2015. Available at http://health. gov/dietaryguidelines/2015/guidelines/. Accessed 8 Nov 2019.

UN 2015. Transforming Our World: The 2030 Agenda for Sustainable Development. https://sustainabledevelopment.un.org/content/documents/21252030\%20Agenda\%20for\%20 Sustainable\%20Development\%20web.pdf. Accessed 8 Nov 2019.

United Nations Children's Fund (UNICEF), World Health Organization, International Bank for Reconstruction and Development/The World Bank. 2018. Levels and trends in child malnutrition: key findings of the 2018 Edition of the Joint Child Malnutrition Estimates. Geneva: World Health Organization; 2018 Licence: CC BY-NC-SA 3.0 IGO.

Varijakshapanicker, P., S. Mckune, L. Miller, S. Hendrickx, M. Balehegn, G.E. Dahl, and A.T. Adesogan. 2019. Sustainable livestock systems to improve human health, nutrition, and economic status. Animal Frontiers 9 (4): 39-50.

Willett, W., J. Rockström, B. Loken, M. Springmann, T. Lang, S. Vermeulen, T. Garnett, D. Tilman, F. DeClerck, A. Wood, and M. Jonell. 2019. Food in the Anthropocene: The EAT-lancet commission on healthy diets from sustainable food systems. The Lancet 393 (10170): 447-492.

World Resources Institute. 2019. Creating a sustainable food future a menu of solutions to feed nearly 10 billion people by 2050 . Washington, DC.

Yakoob, M.Y., R. Micha, S. Khatibzadeh, G.M. Singh, P. Shi, H. Ahsan, N. Balakrishna, G.N. Brahmam, Y. Chen, A. Afshin, and S. Fahimi. 2016. Impact of dietary and metabolic risk factors on cardiovascular and diabetes mortality in South Asia: Analysis from the 2010 global burden of disease study. American Journal of Public Health 106 (12): 2113-2125.

Publisher's Note Springer Nature remains neutral with regard to jurisdictional claims in published maps and institutional affiliations. 